\title{
Germanica
}

dans la littérature, le cinéma et le théâtre

\section{Christelle Brun, Paul Claudel et le monde germanique}

\section{Marine Deregnoncourt}

\section{(2) OpenEdition}

Journals

Édition électronique

URL : https://journals.openedition.org/germanica/11228

DOI : 10.4000/germanica. 11228

ISSN : 2107-0784

Éditeur

Université de Lille

Édition imprimée

Date de publication : 28 juin 2021

Pagination : 198-200

ISBN : 978-2-913857-47-6

ISSN : 0984-2632

Référence électronique

Marine Deregnoncourt, "Christelle Brun, Paul Claudel et le monde germanique », Germanica [En ligne],

68 | 2e trimestre 2021, mis en ligne le 28 juin 2021, consulté le 04 janvier 2023. URL : http://

journals.openedition.org/germanica/11228; DOI : https://doi.org/10.4000/germanica.11228

Ce document a été généré automatiquement le 4 janvier 2023.

Tous droits réservés 


\title{
Christelle Brun, Paul Claudel et le monde germanique
}

\author{
Marine Deregnoncourt
}

\section{RÉFÉRENCE}

Christelle Brun, Paul Claudel et le monde germanique, ouvrage revu et introduit par Monique Dubar, Genève, Droz, 2020, 688 p.

1 Soutenue en 2001, à l'Université de la Sorbonne, sous la direction de Michel Autrand, la thèse de doctorat rédigée par Christelle Brun est consacrée aux relations de Paul Claudel avec le monde germanique. La présidente du jury de thèse de Christelle Brun, Monique Dubar, décide, près de 20 ans après la soutenance, de superviser l'édition de cette thèse, et de la faire paraittre le 3 juillet 2020, en hommage à son autrice, disparue brutalement en 2013.

Doté d'une bibliographie, d'un index des noms et, en annexe, d'une chronologie et d'ouvrages issus de la bibliothèque de Paul Claudel, ce travail, divisé en dix-sept chapitres, décrit les rapports, à la fois continus et complexes, entre Paul Claudel et le monde germanique. Les premiers contacts claudéliens avec la culture germanique datent de sa scolarité au Lycée Louis-le-Grand à Paris. Il y est formé, d'une part, à la littérature par le prisme des œuvres de Lessing, Goethe et Schiller, et, d'autre part, à la philosophie kantienne par l'entremise du professeur Auguste Burdeau. De surcroît, devenu ami avec Romain Rolland, le jeune Claudel découvre les opéras wagnériens. Il se voit ainsi initié à la musique et va grandement admirer les symphonies de Beethoven.

Cette réflexion doctorale est scindée en trois parties. La première concerne les réactions claudéliennes face à la religion, l'art et la pensée allemande à travers les figures de Kant, Luther, Goethe et Wagner. Témoin de la guerre franco-prussienne en 1870 ainsi que des deux guerres mondiales, Paul Claudel rejette initialement, pour le moins violemment, le monde germanique. Ce comportement lui vaut d'ailleurs d'être refusé à un poste d'ambassadeur en Allemagne. Toutefois, l'artiste va, au fil des années 
et des événements politiques, nuancer ses propos. En effet, il rêve déjà d'une concorde et d'une alliance franco-allemande dans son œuvre théâtrale fleuve, Le Soulier de Satin, parue en 1929. Il formalise encore davantage cet ardent souhait en 1953, - soit deux ans avant sa mort, fortement médiatisée par la presse allemande - à Strasbourg, en mentionnant Les Serments de Strasbourg. Le deuxième grand moment de cette étude est dédié aux activités diplomatiques et commerciales de Paul Claudel à Francfort et Hambourg entre 1912 et 1914. En ce qui concerne la troisième et ultime partie de cette monographie, elle s'intéresse, plus spécifiquement, à la diffusion, au rayonnement, à l'interprétation et à la réception de l'œuvre claudélienne en Allemagne. Dans ce cadre, il est question des relations étroites de Paul Claudel avec non seulement les traducteurs, notamment, de son théâtre : Franz Blei, Edwin-Maria Landau et Hans Urs von Balthazar, mais aussi avec les metteurs en scène et ses affinités avec Bertolt Brecht. $\mathrm{Au}$ mois d'octobre 1913 a lieu la première représentation de L'Annonce faite à Marie, traduite en langue allemande, Mariä Verkündigung, par Jacob Hegner. Cet événement se produit au Théâtre d'Hellerau, à la suite de la mise en scène proposée, lors des fêtes de Noël en 1912, par Aurélien Lugné-Poe à Paris. Au mois de mai 1930, c'est au tour du Livre de Christophe Colomb d'être adapté à l'Opéra de Berlin, avec succès; ce qui ravit d'autant plus Paul Claudel qu'il a connu de nombreuses déconvenues en France où son œuvre théâtrale est demeurée incomprise, jusqu'en 1943, quand Jean-Louis Barrault décide de monter Le Soulier de Satin à la Comédie-Française avec Marie Bell dans le rôletitre de Prouhèze. Nous devons ces précieux renseignements aux coupures de presse allemande, scrupuleusement et précisément recensées par Christelle Brun.

Cette étude apparait pionnière et fondatrice à plus d'un titre. Tout d'abord, elle offre un éclairage inédit et novateur sur un pan mal connu et, jusqu'ici, peu étudié de la vie et l'œuvre claudéliennes. Ensuite, une documentation tout particulièrement riche, originale et abondante témoigne de l'étendue des recherches menées de façon exhaustive par Christelle Brun. Ses travaux s'inscrivent dans le sillage de ceux effectués antérieurement par Edwin-Maria Landau et André Espiau de la Maëstre. L'autrice n'a pas hésité à traduire systématiquement les nombreuses citations en langue allemande qu'elle a reprises et citées. Enfin, elle s'est même rendue aux Archives du Quai d'Orsay à Paris afin d'avoir accès aux rapports économiques et financiers de Paul Claudel, rédigés à Francfort et Hambourg, de 1912 à 1914, lors de ses séjours diplomatiques. En définitive, il s'agit là d'une somme érudite et prodigieuse que nous encourageons vivement à lire et à découvrir. 